\title{
Prevention and Control of Plastic Waste Pollution in the Polar Region: A Review.
}

\author{
Mabina Agnes",**, Awomuti Adeboye ${ }^{*, * *}$ Qinghui Huang *,** \\ *UN Environment-Tongji Institute of Environment for Sustainable Development (IESD): College of Environmental Science and Engineering, Tongji University, Shanghai 200092, P.R.China
}

DOI: 10.29322/IJSRP.10.12.2020.p10803

http://dx.doi.org/10.29322/IJSRP.10.12.2020.p10803

\begin{abstract}
The effect and harm done to the marine environment by plastic pollution can never be overemphasized. This research reviews and examined various policies, laws, and regulations that have been put in place to mitigate and control the devastating effects of plastic waste pollution, particular reference was made to the polar region and likely environ. Scientific researches, Journal papers, and various publications on plastic waste pollution in the polar region, also known or interchangeably referred to as the Arctic or Antarctica are also reviewed. Findings show that the threat of plastic waste pollution in the Polar region if not quickly attended to could result in devastating climate and environmental problems. Efforts from intergovernmental and international organizations on the subject matter were also investigated, e.g. United Nations Environment Programme (UNEP) the International Union for Conservation of Nature (IUCN), Arctic Council Organization (ACO), Ocean Conservancy (OC), the Arctic Initiative (AI) and the Polar Institute (PI). Various other Policies, Interventions, and Conventions were also studied and recommendations made in accordance with the conclusions reached. Recommendations made from this review include: promoting awareness and understanding of the plastic pollution issue through targeted communication and education efforts to increase community engagement and solutions co-creation; convene industry to educate about economic and environmental threats from plastic pollution and to generate reasonable and realistic practices for plastic pollution mitigation; work with industry to develop and promote guidelines that reduce plastic waste and address appropriate disposal, recycling and reuse of plastic materials.
\end{abstract}

Key Words- Arctic, Antarctic, Polar, Microplastic, Marine debris, Plastic.

\section{INTRODUCTION}

The quick growth and rise in living standards of individuals have caused an increase in domestic waste[1]. According to an estimate, the global municipal solid waste (MSW) generation has increased by nearly 1.3 billion tons per year in 2010, and it is expected to reach 2.2 billion metric tons per year in 2025. Among this household waste, plastic waste is posing a major threat to human health as well as the environment[2]. Plastics are versatile material of synthetic long-chain polymers with low cost, lightweight, recalcitrant properties, which brings numerous social benefits and becomes an indispensable component of daily life, driving the annual demand for world production on a substantial scale[3-4].
"However, with rapidly growing plastic production from 230 million metric tons (Mt) in 2005 to $322 \mathrm{Mt}$ in 2015, the associated concern must be plastic waste management in that around $6300 \mathrm{Mt}$ of plastic waste have been generated globally by 2015 "[3]. It is estimated that about 5 trillion i.e. over 260, 000 tonnes of plastic garbage now floats on the sea surface worldwide due to indiscriminate waste disposal [1,5-6]. Thus, the global public, with government, environmental NGOs, and science experts, has gradually voiced concern for plastic litter as a significant pollutant in the aquatic ecosystem since the early 1970s. The latest figures indicate that between 4.8 and $12.7 \mathrm{Mt}$ of plastic is generated annually on the world's oceans, with almost one-third of overall pollution from 192 coastline countries and regions becoming China's one of the main aquatic litter generators. Provided there are no changes in plastic waste management on land if existing trends persist, the total amount of plastic waste from land into the oceans by 2025 will rise dramatically [7].

Plastics can broadly fall into four levels based on their sizes: Megaplastics (> $1 \mathrm{~m})$; Macroplastics (< $1 \mathrm{~m})$, Mescoplastics (< $2.5 \mathrm{~cm})$; and microplastics $(<5 \mathrm{~mm})[3]$. "Microplastics" is a collective term and was first proposed, defined as all plastic particles or debris smaller than $5 \mathrm{~mm}$ in diameter including nano plastics (particles with nano-scale) according to the criteria of the US National Oceanic and Atmospheric Administration (NOAA) the microplastics are surpassing the large plastic pollutants, usually found in most popularly manufactured goods such as personal care and cosmetic products (PCCPs), or may derive from the in situ environmental pollution and subsequent fragmentation of large pieces of plastics by physical, chemical and biological processes[8]. Although a novel bacterium was isolated, capable of degrading and assimilating (polyethylene terephthalate) recently, the low energy environment[9-10], low oxygen levels, extreme cold, and lack of solar ultraviolet (UV)-radiation in the benthic zone make the breakdown speed of plastic debris slowdown, further exacerbating the persistence of microplastics in the oceans[3].

It is a known fact that mishandling and mistreatment of plastic waste can cause environmental pollution [11-12]. The decomposition of plastics takes years, which may be an immense danger to the environment. toxic chemicals are released, When plastic is combusted in the air or buried in the soil this further contaminates soil and air, . Countries all over the world, whether developing or underdeveloped, are expected to face environmental degradation and scarcity of natural resources due to mismanagement of resources. In the United Kingdom, the United 
states of America, Finland, Belgium, Brasil, Nordics, and South Africa[13], scientists continue to illustrate plastic risks to the environment[3]. There is currently no proper and appropriate control of plastic waste disposal in developing countries like Pakistan. Pakistan is the sixth most populous country in the world, according to the United States Census Bureau. Pakistan does not have any and restriction on using plastic products; therefore, the problem regarding the waste management is increasing with every passing year. To cope with these problems, proper waste management is required. The recycling/return of waste products is considered to be one of the ways for proper waste management. by the subarctic[15]. The word Arctic comes from the Greek word (arktikos), "near the Bear, northern" and that from the word (arktos), meaning bear. The name refers either to the constellation Ursa Major, the "Great Bear", which is prominent in the northern portion of the celestial sphere, or to the constellation Ursa Minor, the "Little Bear", which contains

Polaris, the Pole Star, also known as the North Star. There are a number of definitions of what area is contained within the Arctic. The area can be defined as north of the Arctic Circle $\left(66^{\circ} 33^{\prime} \mathrm{N}\right)$,

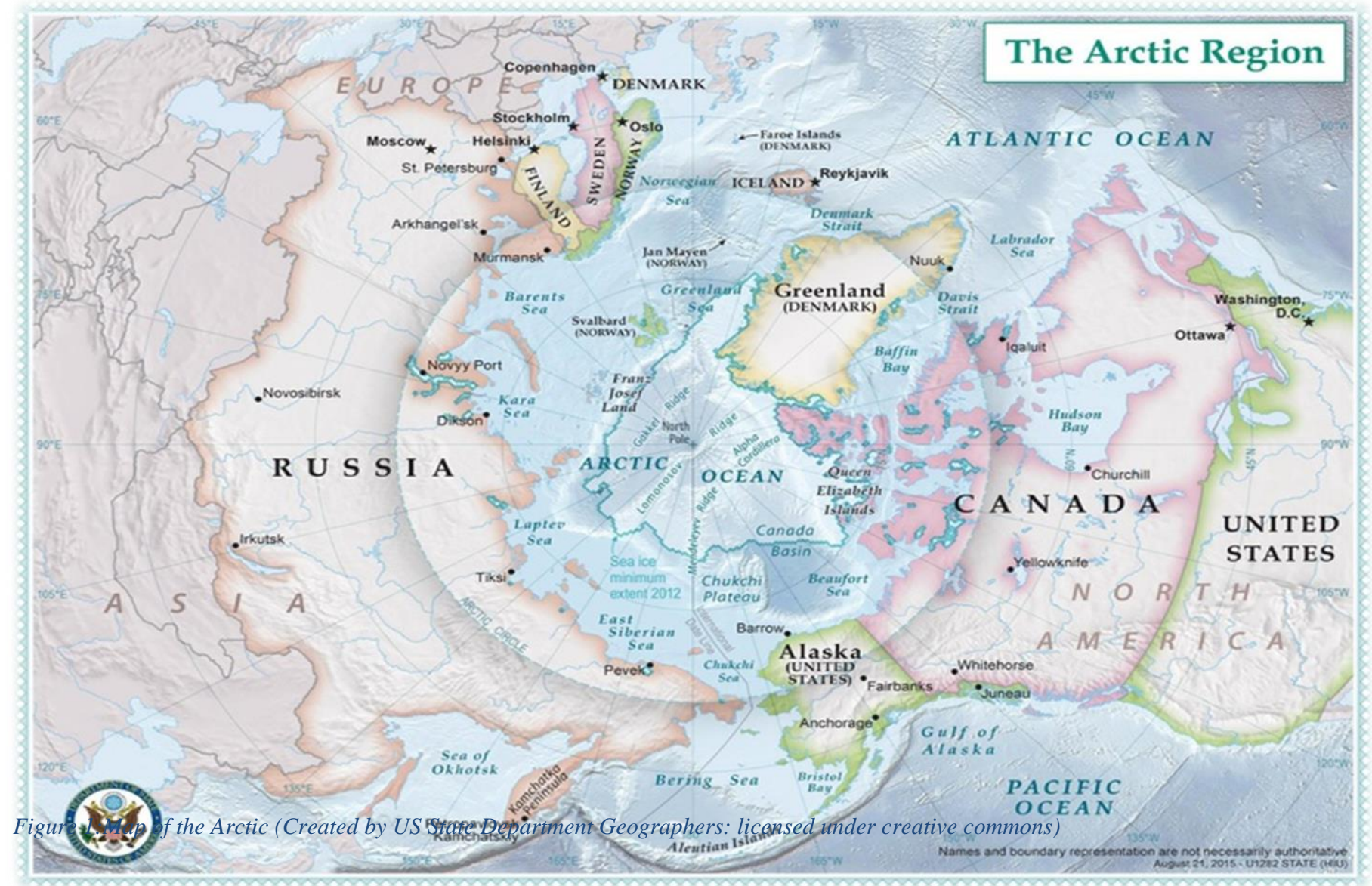

Different researchers have worked on the waste management and environmental protection[10].

\section{The Polar Region}

In the northernmost portion of the World, the Arctic is sometimes known as the polar region [14]. It is composed of Alaska (the U.S.), Canada, Finland, Greenland (Denmark), Iceland, Norway, Russia, and Sweden, as well as the Arctic Ocean and surrounding oceans. Land in the Arctic region has seasonally shifting snow and ice cover and tundra mostly featuring treeless permafrost. Seas of the Arctic comprise in several areas' seasonal sea ice. The Arctic region is a unique area among Earth's ecosystems. The cultures in the region and the Arctic indigenous peoples have adapted to its cold and extreme conditions. Life in the Arctic includes zooplankton and phytoplankton, fish and marine mammals, birds, land animals, plants and human societies. Arctic land is bordered the approximate southern limit of the midnight sun and the polar night. Another definition of the Arctic, which is popular with ecologists, is the region in the Northern Hemisphere where the average temperature for the warmest month (July) is below $10{ }^{\circ} \mathrm{C}$ $\left(50{ }^{\circ} \mathrm{F}\right)$; the northernmost tree line roughly follows the isotherm at the boundary of this region[14].

\section{Climate and Features}

The climate of the Arctic is characterized by long, cold winters and short, cool summers[16]. There is a large amount of variability in climate across the Arctic, but all regions experience extremes of solar radiation in both summer and winter. Some parts of the Arctic are covered by ice (sea ice, glacial ice, or snow) year-round, and nearly all parts of the Arctic experience long periods with some form of ice on the surface. 
The Arctic consists of ocean that is largely surrounded by land. As such, the climate of much of the Arctic is moderated by the ocean water, which can never have a temperature below $-2^{\circ} \mathrm{C}\left(28^{\circ} \mathrm{F}\right)$. Although it is shrouded with polar ice in winter, this comparatively warm water holds the North Pole out of the Northern Hemisphere which is part of the reason that it is much cooler than the Arctic. In the winter months of November through February, the influence of the surrounding oceans prevents coastal regions warming as much as possible, and the sun is very low in the atmosphere of the Arctic or not at all rising. The days are shorter as it rises, and the lower position of the sun in the atmosphere means that not so much sunlight hits the surface except at 12 noon. In comparison, the light snow layer reflects much of the minimal amount of solar radiation hitting the earth. Cold snow reflects the amount of solar radiation touching it from 70 to $90 \%$, and snow covers much of the Arctic land and ice in winter. Both conditions contribute to a marginal input of solar energy into the Arctic in winter; only the transfer of hot air and sea water from the south into the Arctic and heat from the subface and sea (who also recover heat and release it in summer) to surface and air in winter are the key factors stopping the Arctic from continuing to cool all winters. $[14,16]$.

Arctic days in March and April are gradually lengthening and in the atmosphere the sun rises, taking the sun to the Arctic rather than in winter, respectively. Most of the Arctic also has winter temperatures during these early months of the Northern Hemisphere, but with addition of sunshine. The constant low temperatures and the permanent white snow cover mean that this extra energy from the sun in the Arctic has a sluggish effect as it is mostly reflected away without heating the earth. By Can, temperatures increase as 24-hour sunshine enters certain places, while snow cover is still the bulk of the Arctic, therefore, the Arctic area represents more than 70 percent of the sun's energy hitting the Arctic in all areas, except the Norwegian Sea and the Southern Bering Sea. The snow melt in most areas of the Arctic occurs at the end of May or sometime in June. This starts with a feedback that represents lower solar radioactivity $(50 \%$ to $60 \%$ ) than dry snow, meaning that greater energy is consumed and the melting process is increased. The snow on earth will consume much more energy and soon start warming the underlying surfaces[16].

\section{LITERATURE REVIEW}

\section{Instruments of marine microplastics at international, regional, and national levels}

Though there is currently no formal maritime international law on microplastics, there have been several constructive countermeasures - international, regional, and national voluntary or legal binding procedure (Table 1 and 2). There are three international conventions in the early 1970s which resolve plastic waste problems in the marine environment.[13,17-18]: The Convention on the Law for the Sea (UNCLOS 1982) of the United Nations ( UN) as amended by the Protocol of 1978 (Marpol 73/78) as well as the Convention on the Prohibition of Dumping Waste and Other Matters for the Prevention of Contamination by Ships (1973). and in 1972. London Convention (LC). UNCLOS is the most detailed regulatory system in aquatic plastic emissions, addressing international marine and marine science studies, marine environmental health and safety, marine technological advances, exchanges, land dispute advice and adjudication, natural resource management and marine waste treatment. Taking underwater litter contamination into account by shipping or aircraft, MARPOL 73/78 is a general prohibition on intentional dumping of plastics at sea as the most relevant international convention in Annex V[10]. The discharge during the normal operation is not regarded as dumping within the scope of Annex $\mathrm{V}$ in MARPOL 73/78. The LC is a Global agreement, which was later replaced by the London Protocol (LP), 1996, to control coastal waste by dumping persistent plastic and other industrial material on sea.

LP is largely in line with the reverse list precautionary principle and is more conservative than LC's black and grey lists. The Secretariat is to commission, in the form of the United Nations Environment Program (UNEP)-led Global Partnership on Marine Litter (GPML) due to concerns related to marine microplastics, including multiple waste sources under the LC/LP, a 'Record on the existing condition of the marine litters in wastes dumped in the sea under the London Convention and Protocol'[5,19]. Other key international agreements, frameworks, programs, such as the UN' s Code of Ethics for the Responsible Fisheries for Food and Agriculture, Agenda 21: Rio de Janeiro UN Action Policy and Johannesburg Development Plan and Biological Diversity Convention (1992), with a Jakarta Mandate on Conservation and Sustainable Naval Usage Other important international agreements and structure and initiatives Universal UNEP projects are also being created in order to design and introduce regional activities at the 12 regional Pilot Sea (Baltic Sea, Black Sea, Caspian Sea, East Asian Sea, Eastern Africa, North-East Atlantic, North-West Pacific , South Asian Seas, and Gulf of Aden) and to promote regional activities at regional level. Global initiatives on the Regional Sea Programe (RSP, 1974) and Global Program of Action (GPA, 1995) are being developed in response to the threats posed by marine litter in 2003 including: Evaluation and measurement of Marine Litter status in each region; organization of a national regional conference and marine litter experts; drawing up a regional action plan (or regional strategy) for a safe handling of Marine Litter in each region; regional clean-up days as part of the International Clean-up Program for Coastal Coastal Affairs; [3].

As global environmental governance has also been motivated by the pressing problem of reducing polar area emissions like marine microplastics, a substantial number of global mechanisms and policies in recent years have been adopted directly or indirectly[20-21]. In 2012, 64 countries and the European Commission adopted the Manila Declaration under the Global Action Program for the Conservation of the Polar Area Ecosystem from Land Based Operations, in order to stop land-based marine litters, which also decided to create a GPML to integrate marine waste sources in the sea.[22-23]. The G7 (2015) world leaders have recognised the value of aquatic litters with a determination to make this topic a priority. The focus of the G7 Meeting was on 
"Better Protection - Linking Regions - Commons Governance: Knowledge of and Monitoring of maritime areas; peaceful conflict resolution; illicit, unregulated and unreported fishing; and maritime security networking. The G7 Summit (2015) introduced the Aquatic Debris Action Plan covering land and sea sources, raising consciousness, raising public awareness, and eliminating events. More recently, the G20 Summit (2017) has released a paper confirming and reviewing a 2030 Agenda Action Plan on G20 Sustainable Development Targets - one of the three key sustainability projects of the G20 Aquatic Litter Action Plan. Meanwhile, it is also an available approach to adopt a "circular economy" for recycling and reusing materials and reducing waste, contributing to preventing land-based waste from entering the oceans[24].

Table 1:Summary of International legislation, regulations, and instruments related to microplastics

\begin{tabular}{|c|c|c|}
\hline International Instruments & $\begin{array}{l}\text { Chronological } \\
\text { Timeline }\end{array}$ & Policy content and Excerpts \\
\hline London Convention & 1972 & $\begin{array}{l}\text { Aimed at preventing the "deliberate disposal at sea of wastes and other } \\
\text { matter from vessels, aircraft and other structures, including the vessels } \\
\text { themselves". (Annex I, paragraph 2) }\end{array}$ \\
\hline MARPOL 73/78 & 1973 & $\begin{array}{l}\text { To prohibits "the disposal into the sea of all plastics, cargo residues, fishing } \\
\text { gear including but not limited to synthetic ropes, synthetic fishing nets and } \\
\text { plastic garbage bags". Through Annex V (revised in } 2011 \text { and implemented } \\
\text { in 2013) }\end{array}$ \\
\hline $\begin{array}{l}\text { United Nations Convention } \\
\text { on the Law of the Sea }\end{array}$ & 1982 & $\begin{array}{l}\text { Regulations on stringent control of marine pollution and contamination } \\
\text { from sea-/ land-based sources.: Part XII (Articles 192-237) }\end{array}$ \\
\hline Basel Convention & 1989 & $\begin{array}{l}\text { Guidelines on plastic waste and microplastics matters. Discussed at the } \\
\text { Basel Convention workstream COP } 13 \text { (Plastic waste in Annex II Y } 46 \\
\text { (Household wastes) and Annex VIII (Non-hazardous wastes) }\end{array}$ \\
\hline London Protocol & 1996 & $\begin{array}{l}\text { Strategies to prevent the "dumping of any wastes or other matter } \\
\text { including the export of waste to countries for dumping and incineration at } \\
\text { sea except for the materials listed in Annex I".: (Article 4.1.1, } 5 \text { and 6) }\end{array}$ \\
\hline $\begin{array}{l}\text { UNEP - Regional Seas } \\
\text { Programme and Global } \\
\text { Programme of Action }\end{array}$ & 2003 & $\begin{array}{l}\text { Ammonization of purpose and rules for Regional Cooperation surveillance } \\
\text { in } 12 \text { regional seas }\end{array}$ \\
\hline Manila Declaration & 2012 & $\begin{array}{l}\text { Prevention of marine pollution from land-based sources and agreement to } \\
\text { establish a Global Partnership on Marine Litter (GPML) }\end{array}$ \\
\hline G7 Summit & 2014 & G7 Marine Litter Action Plan (MLAP) \\
\hline $\begin{array}{l}\text { United Nations Environment } \\
\text { Assembly (UNEA) I }\end{array}$ & 2014 & Resolutions 1/6: Discussions on "Marine plastic debris and microplastics". \\
\hline UNEA II & 2016 & $\begin{array}{l}\text { Resolutions 2/11: Measures to reduce marine plastic litter and } \\
\text { microplastics }\end{array}$ \\
\hline G20 Summit & 2017 & G20 Marine Litter Action Plan \\
\hline UNEA III & 2017 & $\begin{array}{l}\text { Resolutions 3/7: Strategies to combat the spread of marine plastic litter and } \\
\text { microplastics. }\end{array}$ \\
\hline
\end{tabular}

The first session of the United Nations Environment Assembly (UNEA I, 2014) put forward the issue of plastics (including that microplastics in the marine environment are a rapidly increasing problem) finally adopted Resolutions $1 / 6$ on marine plastic debris and microplastics[25]. It also requests to undertake a study on marine plastic debris and marine microplastics. Meanwhile, the Secretariats of the Stockholm Convention, the Basel Convention, and relevant organizations are invited to be involved in pollution control and chemicals and waste management, to contribute to the analysis above. UNEA II (2016) has accomplished, under the overall theme of the implementation in 2030 of the Sustainable Development Plan (17 targets), to reach a consensus on resolution $2 / 11$ on aquatic plastics and microplastics. Goal 14 outlines its 14.1 goal which aims to "prevent and substantially reduce marine pollution of all sorts, including marine debris and nutrient pollution, by 2025 in particular by land-based activities." Along with recognizing the importance of cooperation between the UNEP and conventions and international instruments related to preventing and minimizing marine pollution from waste, it stresses that prevention and environmentally sound management (ESM) of waste are keys to long-term success in combating marine pollution, including marine plastic debris and microplastics. And it requests to undertake an assessment of the effectiveness of 
relevant international, regional, and sub-regional governance strategies and approaches to combat marine plastic litter and microplastics. In the recent UNEA III (2017), Resolution 3/7 on marine plastic debris and microplastics was adopted, stressing the importance of long-term elimination of the discharge of litter and microplastics to the oceans, of avoiding detriment to marine ecosystems and the human activities dependent on them from marine litter and microplastics, urging all actors to step up actions to "by 2025 , to prevent and significantly reduce marine pollution of all kinds, in particular from land-based activities, including marine debris and nutrient pollution", and also encouraging all Member States to prioritize policies and measures[26-28]. Plastic waste and microplastics issues have also been included into the Basel Convention (Basel Convention on the Transboundary Movements of Hazardous Wastes and their Disposal) workstream at the 13th Conference of Parties in 2017, to encourage interested regional and sub-regional centers to work under the Convention on the impact of plastic waste, marine plastic litter, microplastics, and take measures for prevention and ESM, as well as introduce the above detailed new work into the 2018-2019 work program.

\section{DISCUSSIONS}

\section{Regional and national instruments}

This section provides an outline of some of the more advanced aquatic plastic issues instruments that contain legislation, programmes and action plans drafted at a state and national level that do not span the spectrum of current interventions. A range of regulations, laws and measures aimed at marine litter interventions have been adopted by the European Union ( EU), which effectively contributes significantly to international attempts to avoid, eliminate and minimise marine litter, including the European Directive on the Marine Strategy Framework Directive (MSFD)[17]. The Directive was the first EU-wide law on biodiversity conservation and was adopted on 17 June 2008. It aims to help protect and achieve the aquatic ecosystem in Europe Good Environmental Status (GES) of EU marine waters by 2020. The MSFD defines GES as: "the environmental status of marine waters where these provide ecologically diverse and dynamic oceans and seas which are clean, healthy and productive".

Table 2:Summary of current regional and national instruments related to microplastics

\begin{tabular}{|c|c|c|}
\hline Regional/National Instruments & $\begin{array}{l}\text { Chronological } \\
\text { Timeline }\end{array}$ & Policy content and Excerpts \\
\hline European Union (EU) & 2008 & $\begin{array}{l}\text { The first EU legislative instrument related to the protection of marine } \\
\text { biodiversity }\end{array}$ \\
\hline $\begin{array}{l}\text { United States: National Strategies } \\
\text { on the control of microbeads in } \\
\text { personal care products, cosmetics, } \\
\text { and non-prescription drugs (MSFD) }\end{array}$ & $\begin{array}{l}2011 \\
2015 \\
2017 \\
2018 \\
2019\end{array}$ & $\begin{array}{l}\text { Honolulu Strategy } 2011 \\
\text { Microbead-Free Waters Act } \\
\text { Ban on manufacturing rinse-off products containing plastic microbeads } \\
\text { Ban on delivery of rinse-off products containing plastic microbeads } \\
\text { Ban on manufacture and delivery of rinse-off products containing PM }\end{array}$ \\
\hline $\begin{array}{l}\text { Canada: SOR (111) } \\
\text { Regulations on Microbeads in } \\
\text { Toiletries: cosmetics, natural } \\
\text { health products, and non- } \\
\text { prescription drugs }\end{array}$ & $\begin{array}{l}2017 \\
2018 \\
2019\end{array}$ & $\begin{array}{l}\text { Policy suggestions to prohibit the use of Microbeads in Toiletries } \\
\text { Ban on manufacturing and importation of toiletries containing microbeads } \\
\text { Ban on the use or sale Natural health products and/or non-prescription drugs } \\
\text { containing microbeads }\end{array}$ \\
\hline UK & $\begin{array}{l}2017 \\
2018\end{array}$ & $\begin{array}{l}\text { Discussions to ban the rinse-off of cosmetics products containing microbeads } \\
\text { Ban on the manufacture of the products discussed in } 2017\end{array}$ \\
\hline Australia & 2017 & Legislation and eventual prohibition of the use of microbeads in any product \\
\hline South Korea & 2018 & Ban on the use and sale of plastic microbeads in all cosmetics \\
\hline Sweden & 2018 & Ban on microbeads in rinse-off products \\
\hline Taiwan Province, China & 2018 & Ban on the manufacture, sale and import of products containing microbeads \\
\hline New Zealand & 2018 & $\begin{array}{l}\text { World Trade Organization informed of draft regulation: ban on microbeads in } \\
\text { personal care products }\end{array}$ \\
\hline Italy & 2019 & $\begin{array}{l}\text { Ban on microbeads scrubs particles in cosmetics }-2020 \text {. Ban on plastic cotton } \\
\text { buds }-2019 \text {. }\end{array}$ \\
\hline
\end{tabular}


Annex III of the Directive was also amended in 2017 to better link ecosystem components, anthropogenic pressures, and impacts on the marine environment with the MSFD's 11 descriptors and with the new Decision on GES[29]. The EU and the European Commission ( EC) have already developed a series of detailed requirements and methodological principles to support the introduction by Member States of the Marine directive and other European marine waste litter regulations including EU Directive for port waste and cargo waste reception facilities (EC2000/59); EU Bathtube Directive (76/160 / EEC and 2006/7 / EC); EC Urban Waste Water Directive (EC2000/59) and the European Commission ( EC); Most developing countries at state level have implemented policies and policy initiatives for coping with microplastics. The plastics industry in the US and UK has implemented "Operation Clean Sweep" to reduce plastic pellet loss to the environment especially during transportation and shipment. However, the measures taken by developed countries on microplastic beads are mostly limited to PCCPs[30-31]. And commercial raw materials microplastics are currently in the testing stages. The US NOAA specially developed the National Marine Debris Program (NDP) in 2006, along with the UNEP in 2011. The policy can be viewed as a holistic, global mechanism for attempts to reduce the biological, human and economic effects of marine litter in which plastics (including microplastics) are used as marine environmental contaminants. Illinois becomes the first US state to adopt regulations that forbids the manufacturing and distribution, by the end of the year 2017, of goods containing microbeads from 2014 to 2015 next to one of the world's biggest freshwater bodies of water, Lake Michigan. New Jersey followed suit, and there are a number of other states focused on the issue, including Michigan, New York and Indiana. In late December 2015, the US signed the Microbead-Free Waters Act, according to which, on 1 July 2017, no cosmetics containing plastic microbeads will be approved by all manufacturers, and that such items must, joined to insist that the EU ban microbeads from personal food goods in 2015, expressing their clear fears at the possible threat to human health by gradually being marine. Sweden's own ban on microbeads on rinse-off goods has also been implemented (Swedish Government, 2015) and will be released in January 2018. Following the actions taken by the US in mid-2017, the UK Government has announced its intention to ban the 2018 ban and 2017 manufacture of rinse-o-off cosmetic items containing microbeads.[30,32]. In addition, Beach Cleanup and other literacy projects have been carried out in Britain, including the Green Blue project. On 19 December 2017, the Italian parliament approved a resolution banning the use of cosmetics by microbeads by 2020 . Italy will now become the first country to ban cotton plastic buds from 2019. The Canadian government has declared a thorough ban on the sale of plastic microbeads containing shower gels, toothpaste and face scrubs effective July 1, 2018 which will set the timeline for Canada in keeping with the US to remove the small pollutant from Canadian waters. A year later 1 July 2019, the ban will be issued to microbeads discovered in herbal and nonprescription narcotics.

New Zealand has conveyed to the World Trade Organisation ( WTO), which will take effect in 2018, a ban on the management of micro-beads on personal care goods. In Australia (2016), if businesses do not willingly phase out micro-beads by 1 July 2017 , the Federal Government shall enact legislation to enforce the prohibitions under statute in 2017. Similarly, from July 2018, South Korea will ban the use and sale in all cosmetics of plastic microbeads. Taiwan's county, China, is barred from producing and importing goods containing microbeads on 1 January 2018, with its sales moratorium taking effect on 1 July 2018.[17]. Taiwan Province, China has released a draught bill involving methods for qualitative screening of microbeads. China has not yet released microplastics or microbeads regulatory papers. These tools,
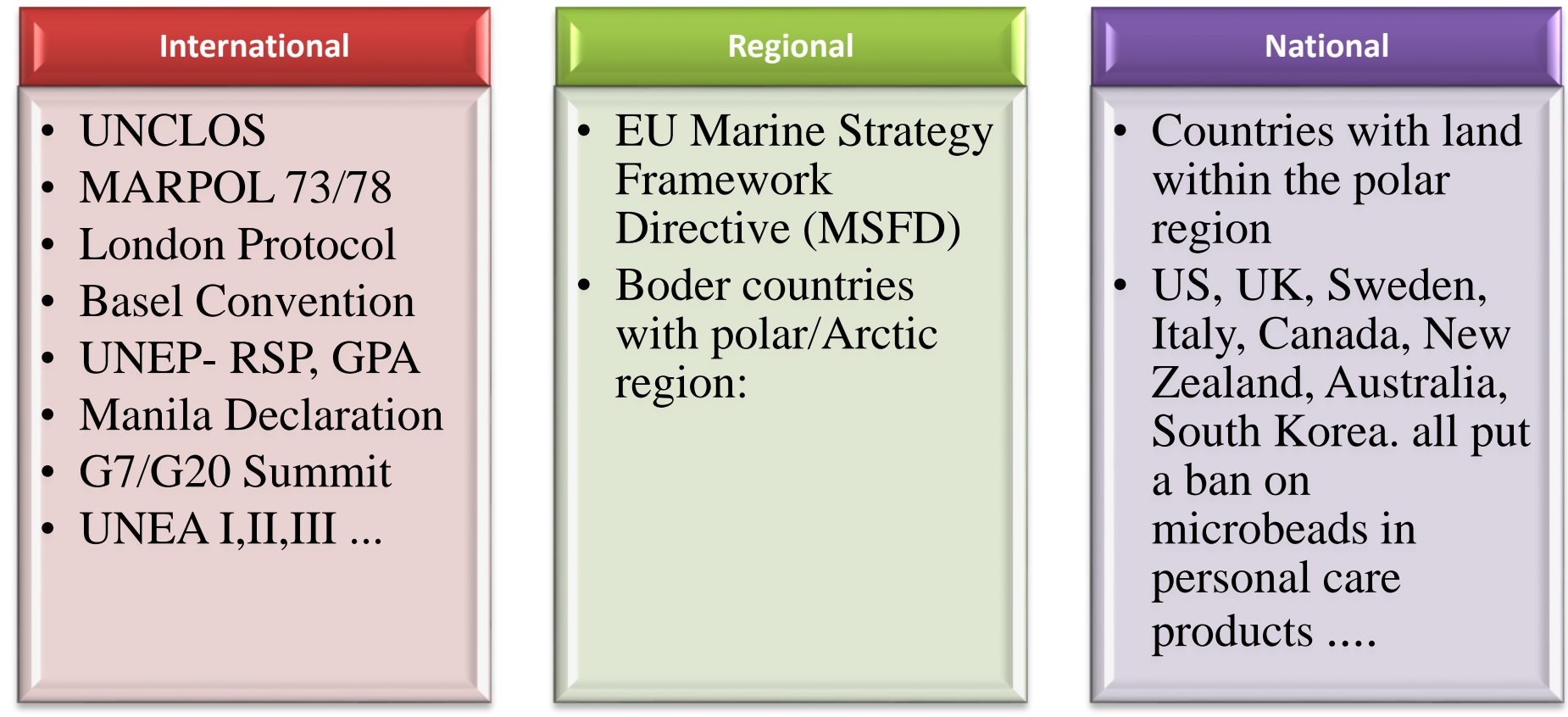

as of 1. July 2018, also be banned. In Europe, five nations -

including conferences, action plans, UNEP RSP, GPA, GPML, Austria, Belgium, Luxembourg, the Netherlands, and Sweden and an interdiction of microbeads at national and international

Figure 2: Regulation and management Frameworks on marine litter across international, regional, and national levels 
levels (in Tables 1 and 2). They also offer a forum for encouraging all actors to collaborate and to exchange international perspectives and practice.[3].

\section{Sources of Plastic Waste in the Polar Region}

Plastic waste is not resistant to Arctic currents, lakes, tides, and winds. In Arctic plastic pollution, the underwater ice, sediments and even the remains of Arctic birds and dolphins are present on the beaches and pools of water in the sea. There is no sufficient knowledge of how plastic flows into and from Arctic waters and the threats to Arctic life and livelihoods plastics present[33].

Every year, over 300 million tons of plastic are produced, half of which is used to design single-use items such as shopping bags, cups and straws[34]. At least 8 million tons, from surface water and sediment from the deep seas, result in our waters each year and make up $80 \%$ of all aquatic waste. The most abundant pieces of aquatic debris are floating plastic waste.

Most marine plastics come from terrestrial sources, including municipal and storm fluxes, overflows of garbage, tourists to the beaches, poor recycling and management, factory operations, construction, and illegal dumping. Ocean-based sources come primarily from the fishery, nautism and aquaculture sectors[35].

The bad news is that plastic never goes anywhere when it is dumped into our oceans. It is not physically degrading[36]. It is literally broken into small particles called micro- and nanoplastics by natural forces, such as solar UV, wind, currents, etc. The social, economic, and ecological effect of plastic waste is important. Marine plastics pose a risk to ocean sustainability, human health, fish safety and coastal tourism.

But the good news is that these issues can be addressed by intervention. IUCN has developed numerous theoretical works to increase awareness of the degree of plastic waste and supports both the Baltic Sea and the Mediterranean strategy and programmatic action. Although the global issue of aquatic plastics demands local and regional solutions tailored to the numerous plastic sources and routes into the ocean.[34].

\section{Stopping the Flow of Plastic Waste to the Polar Region}

Islands are particularly vulnerable to plastic contamination as remote areas are a major challenge in the organization of interIceland waste logistics. The restricted resources of the Islands contribute to major and additional difficulties relative to their continental counterparts[37]. The latest initiative "Plastic Waste Free Islands" intends to increase the acceptance by the Caribbean, the Mediterranean, and the Pacific of initiatives for limiting plastic leakage across the tourism, fisheries, and waste management sectors. The project also intends to develop sector-specific alternate value chains action plans.[34].

\section{Collaboration: A Key Strategy}

A series of public and private efforts have recently appeared on multinational, federal, domestic, and local levels to counter plastic waste at various points in the plastic chain. A cohesive big picture can be split into various programmes on different stages, complicated, and hard to remove. That is why the differences between the different actor classes need to be bridged and steps taken toward shared objectives, such as Sustainable Development Goals (SDGs)[28,38]. The initiative would also establish a blueprint for islands that federal bodies will support. The draught would set the proposed solution of the IUCN to mitigate plastic leakage on the islands on the basis of the plan for the project and learned lessons.[34].

\section{Global Interventions to Control Marine and Polar Region Plastic Waste Pollution}

\section{Plastic Waste Free Islands}

IUCN initiated the Plastic Waste Free Islands initiative in 2019 with the sponsorship of the Norwegian Development Cooperation Agency (NORAD). The ultimate aim of the initiative is to eliminate plastic spills into the ocean from six SIDS (the Pacific Island) and three Caribbean Islands (the Pacific)[39]. The project also aims to repurpose waste into commercially viable products, thereby generating job opportunities and income for local communities. Key regional bodies will also develop and endorse a blueprint for looking at entire value chains, from production to disposal, and at plastic usage and wastage in different sectors (such as tourism and fisheries). The regional bodies should recognize additional opportunities to extend the use of the blueprint which can be used by any island nation.

\section{Plastic Waste Free Islands - Mediterranean}

With support from the Didier and Martine Primat Foundation, IUCN launched the Plastic Waste Free Islands project in 2019. The overarching goal of the project is to reduce plastic leakage to the ocean from two islands in the Mediterranean Sea. The project also aims to repurpose waste into commercially viable products for sale, thereby generating job opportunities and income for local communities. Key regional bodies will also develop and endorse a blueprint for looking at entire value chains, from production to disposal, and at also plastic usage and wastage in different sectors (such as tourism and fisheries)[40]. These regional bodies will also be able to identify further opportunities to scale up the blueprint's application, which can be used by any island country.

Marine Plastics and Coastal Communities - MARPLASTICCs In late 2017 IUCN initiated an initiative on aquatic plastics and marine coastal ecosystems in the Indian Ocean and Asia-Pacific regions with the assistance of the Swedish International Development Cooperation Agency (SIDA). The overarching aim of this three-year project is to encourage, implement and execute regulations and other appropriate steps to control and mitigate aquatic emissions from plastics in Eastern and Southern Africa and Asia regions. In this, IUCN will invest efforts to provide awareness, power, policy options and action plans for 
management of plastic waste to governments, industry and community in Eastern and Southern Africa and the regions from Asia.[34].

\section{PlastiMed}

IUCN made new attempts to shut down the Mediterranean plastic tap in 2017. This two-year initiative seeks to foster our awareness of plastic sources from source to sea and to help establish local solutions.

\section{PlastiMed BeMed: Closing the plastic tap}

In 2018, IUCN initiated an initiative with the sponsorship of the Prince Albert II Foundation, with the goal of developing current plastic waste and leakage evaluation methodologies, template and data by integrating modelling and field-based methods in the Mediterranean, with an emphasis on the Northern African Countries.

Tackling marine plastics in Thailand: from community-based actions to policies (Phase 1)

The Step 1 (2018-2019) initiative, sponsored by the Coca-Cola Foundation, aims to raise awareness, and improve people's actions for the treatment of solid waste in major strategic places in Thailand. The final aim is to reduce marine plastic emissions dramatically and to catalyse crucial reforms in local and domestic plastic waste management policies.

\section{Baltic Solutions to Plastic Pollution}

The Global Marine and Polar Program (GMPP) with the help of the Swedish Postcode Foundation is working to show the climate change, ecology, and food safety implications of plastic contamination in the Baltic Region. In order to perform desk and field studies and laboratory studies, GMPP has brought together a network of scientists to provide solid scientific proof of the harmful environmental and Social effects of plastic waste within the area. GMPP will explore legislation leveraging frameworks and include access points for recommendations on this basis along with leading regional experts and grassroots organisations.[41].

\section{PlastiCoco}

Placing on the status of aquatic plastic waste in priority regions is the goal of the PlastiCoco initiative, with funding from the Agence Française de Développement (AFD). The initiative, which began in 2018 and will conclude in 2021, will also provide advice on how sustainable aquaculture can be accomplished. The introduction and distribution of these information items at appropriate forums will direct policy making and maritime spatial planning at the state, national and regional level.

\section{Azorlit - Establishing a Baseline on Marine Litter in the Azores}

A thorough awareness of aquatic plastic emissions in the Azores archipelago is desperately needed in order to take appropriate management steps. The project "Azorlit - Creating a Benchmark for Aquatic Litters in the Azores" was planned to resolve these disparities and fundamental concerns in relation to this increasing environmental problem. Project aims were to record the resources and composition of debris on the seashore and in select aquatic species and to measure plastic consumption.[30,42]. The project also aimed at providing support through activities on the sea , especially with the children and adolescents, to the local NGO, the Azores Sea Observatory, (OMA).

\section{CONCLUSION}

From what we have been able to review; various stakeholder industries can be Mobilized to enlighten the public about plastic waste economic and environmental risks and develop fair and practical initiatives to minimize plastic contamination.

Regional government coalition should also be encouraged to construct and encourage policies on plastic waste mitigation and the effective treatment and recycling of plastic products with industries.

It will be in the interest of the Polar Region to develop subregional and local efforts and communications initiatives adapted to individual regional needs and demands.

Stake holders should make conscious efforts to Share details on the promising initiatives already taking place in the polar region in order to maximize and improve the efforts on Arctic plastic waste mitigation.

Indigenous councils should always congregate efforts with incorporation of local cultures where necessary.

Increased investment in creative strategies from people in the Arctic for plastics mitigation, reuse, recycling, and recovery is advised.

Compel more manufacturer obligation to pay for management of environmental costs and impacts associated with a product during its life cycle, and minimize the use of plastics that cannot be recycled

\section{REFERENCES}

C. S. Lam et al., "A Comprehensive Analysis of Plastics and Microplastic Legislation Worldwide," (in English), Water Air Soil Poll, vol. 229, no. 11, Nov 2018

S. B. Borrelle et al., "Predicted growth in plastic waste exceeds efforts to mitigate plastic pollution," (in English), Science, vol. 369, no. 6510, pp. 1515-+, Sep 18 2020

J. J. Wang, L. X. Zheng, and J. H. Li, "A critical review on the sources and instruments of marine microplastics and prospects on the relevant management in China," (in English), Waste Manage Res, vol. 36, no. 10, pp. 898911, Oct 2018

[4] S. Matthews, A. E. Toghyani, H. Eskelinen, L. Luostarinen, T. Karki, and J. Varis, "Method for Limiting Waste in Wood Plastic Composite Post-Production by Means of Press Unit Control Parameters Utilizing Temperature-Related Dimensional Changes," (in English), Bioresources, vol. 12, no. 3, pp. 5118-5127, 2017

E. Foschi, F. D'Addato, and A. Bonoli, "Plastic waste management: a comprehensive analysis of the current status to set up an after-use plastic strategy in Emilia- 
Romagna Region (Italy)," (in English), Environ Sci Pollut R, Mar 142020

[6] F. Khan, W. Ahmed, A. Najmi, and M. Younus, "Managing plastic waste disposal by assessing consumers' recycling behavior: the case of a densely populated developing country," (in English), Environ Sci Pollut $R$, vol. 26, no. 32, pp. 33054-33066, Nov 2019

[7] M. Asari, M. Tsuchimura, S. Sakai, M. Tsukiji, and F. Sagapolutele, "Analysis of mismanaged plastic waste in Samoa to suggest proper waste management in Pacific island countries," (in English), Waste Manage Res, vol. 37, no. 12, pp. 1207-1216, Dec 2019

[8] J. Gong and P. Xie, "Research progress in sources, analytical methods, eco-environmental effects, and control measures of microplastics," (in English), Chemosphere, vol. 254, Sep 2020

[9] A. Adeboye, B. Xu, R. t. Erik, and O. Tamara, "Covid19 and the Impact on Energy Consumption: An Environmental Assessment of Ontario Canada," International Journal of Scientific and Research Publications (IJSRP), vol. 10, no. 8, pp. 857-865, 2020

[10] T. Ahmed et al., "Biodegradation of plastics: current scenario and future prospects for environmental safety," (in English), Environ Sci Pollut R, vol. 25, no. 8, pp. 7287-7298, Mar 2018

[11] X. H. Wu et al., "Investigation of the physical and chemical characteristics of rural solid waste in China and its spatiotemporal distributions," (in English), Environ Sci Pollut R, vol. 25, no. 18, pp. 17330-17342, Jun 2018

[12] H. B. Duan, J. K. Hu, Q. Y. Tan, L. L. Liu, Y. J. Wang, and J. H. Li, "Systematic characterization of generation and management of e-waste in China," (in English), Environ Sci Pollut R, vol. 23, no. 2, pp. 1929-1943, Jan 2016

[13] K. Raubenheimer and A. Mcllgorm, "Can the Basel and Stockholm Conventions provide a global framework to reduce the impact of marine plastic litter?," (in English), Mar Policy, vol. 96, pp. 285-290, Oct 2018

[14] Wekipedia. "The Arctic: A Separated World." https://en.wikipedia.org/wiki/Arctic (accessed.

[15] N. B. Ngoc, N. Bott, and P. N. Diep, "Spectral properties of the surface reflectance of the northern polar region of Mercury," (in English), Res Astron Astrophys, vol. 20, no. 3, Mar 2020

[16] Wikipedia. "Polar Climates: The Extremes of Ice." https://en.wikipedia.org/wiki/Climate of the Arctic (accessed.

[17] K. Willis, C. Maureaud, C. Wilcox, and B. D. Hardesty, "How successful are waste abatement campaigns and government policies at reducing plastic waste into the marine environment?," (in English), Mar Policy, vol. 96, pp. 243-249, Oct 2018

[18] P. S. Kumar and G. Sankaranarayanan, "Investigation on environmental factors of waste plastics into oil and its emulsion to control the emission in DI diesel engine," (in English), Ecotox Environ Safe, vol. 134, pp. 440-444, Dec 2016

[19] M. Anshassi, S. Laux, and T. G. Townsend, "Replacing Recycling Rates with Life-Cycle Metrics as Government
Materials Management Targets," (in English), Environ Sci Technol, vol. 52, no. 11, pp. 6544-6554, Jun 52018 P. C. Tyagi, "Policy, Law and Implementation of Industrial Waste-Water Pollution-Control," (in English), Water Sci Technol, vol. 24, no. 1, pp. 5-13, 1991

H. Wiesmeth, N. Shavgulidze, and N. Tevzadze, "Environmental policies for drinks packaging in Georgia: A mini-review of EPR policies with a focus on incentive compatibility," (in English), Waste Manage Res, vol. 36, no. 11, pp. 1004-1015, Nov 2018

[22] S. B. Sheavly and K. M. Register, "Marine debris \& plastics: Environmental concerns, sources, impacts and solutions," (in English), J Polym Environ, vol. 15, no. 4, pp. 301-305, Oct 2007

[23] K. Raubenheimer and A. McIlgorm, "Is the Montreal Protocol a model that can help solve the global marine plastic debris problem?," (in English), Mar Policy, vol. 81, pp. 322-329, Jul 2017

[24] Y. Ji et al., "Counteractive effects of regional transport and emission control on the formation of fine particles: a case study during the Hangzhou G20 summit," (in English), Atmos Chem Phys, vol. 18, no. 18, pp. 1358113600, Sep 252018

[25] F. Gallo et al., "Marine litter plastics and microplastics and their toxic chemicals components: the need for urgent preventive measures," (in English), Environ Sci Eur, vol. 30, Apr 182018

[26] H. Yasunaga, "Report on Public Lecture Program "Marine Plastic Waste Problems and Current Status/Future of Microplastics Pollution"," (in Japanese), Sen-I Gakkaishi, vol. 76, no. 3, pp. 119-120, Mar 2020

[27] J. J. Ruan, B. J. Qin, and J. X. Huang, "Controlling measures of micro-plastic and nano pollutants: A short review of disposing waste toners," (in English), Environ Int, vol. 118, pp. 92-96, Sep 2018

[28] Z. S. Mazhandu and E. Muzenda, "Global Plastic Waste Pollution Challenges and Management," (in English), Int Renew Sust Energ, pp. 980-987, 2019

[29] R. M. Sebastian, D. Kumar, and B. J. Alappat, "Easy Estimation of Mixed Municipal Solid Waste Characteristics from Component Analysis," (in English), J Environ Eng, vol. 145, no. 11, Nov 12019

[30] M. Eriksen, F. Borgogno, P. Villarrubia-Gomez, E. Anderson, C. Box, and N. Trenholm, "Mitigation strategies to reverse the rising trend of plastics in Polar Regions," (in English), Environ Int, vol. 139, Jun 2020

[31] V. Andrea, P. Mpeza, D. Barelos, and C. Stylios, "Unraveling the Role of Plastic Waste Pollution in the Amvrakikos Wetlands National Park, Greece: The Stakeholders' Views," (in English), J Mar Sci Eng, vol. 8, no. 8, Aug 2020

[32] F. Ronchi et al., "Fishing for Litter in the Adriatic-Ionian macroregion (Mediterranean Sea): Strengths, weaknesses, opportunities and threats," (in English), Mar Policy, vol. 100, pp. 226-237, Feb 2019

[33] T. A. Council. "Plastics in the Arctic." The Arctic Council. https://arcticcouncil.org/en/explore/topics/ocean/plastics/ (accessed 26-08, 2020). 
[34] IUCN. "Closing the Plastic Tap." International Union for Conservation of Nature. https://www.iucn.org/theme/marine-and-polar/ourwork/close-plastic-tap-programme (accessed 13-092020, 2020).

[35] T. Wang et al., "Emission of primary microplastics in mainland China: Invisible but not negligible," (in English), Water Res, vol. 162, pp. 214-224, Oct 12019

[36] G. Nhamo, "Policy instruments for eliminating plastic bags from South Africa's environment," (in English), Ecosystems and Sustainable Development V, vol. 81, pp. 397-406, 2005

[37] M. E. Portman and R. E. Brennan, "Marine litter from beach-based sources: Case study of an Eastern Mediterranean coastal town," (in English), Waste Manage, vol. 69, pp. 535-544, Nov 2017

[38] L. Muliawaty, "The Gober Team as One of the New Waste Management Systems (WMS) in Bandung City," (in English), Proceedings of the International Conference on Public Policy, Social Computing and Development 2017 (Icoposdev 2017), vol. 141, pp. 98102, 2017

[39] F. Oosterhuis, E. Papyrakis, and B. Boteler, "Economic instruments and marine litter control," (in English), Ocean Coast Manage, vol. 102, pp. 47-54, Dec 2014

[40] A. A. A. a. O. O. A.A. Emmanuel, "Administration of Mare as a Contemporary Tourist Festival in Idanre Town of Ondo State, Nigeria," Journal of Geography, Environment and Planning Environmental Issues no. 12, 2013
[41] S. K. Shin, N. Um, Y. J. Kim, N. H. Cho, and T. W. Jeon, "New Policy Framework with Plastic Waste Control Plan for Effective Plastic Waste Management," (in English), Sustainability, vol. 12, no. 15, Aug 2020

[42] G. Dell'Ariccia et al., "Comment on "Marine plastic debris emits a keystone infochemical for olfactory foraging seabirds" by Savoca et al.," (in English), $S c i$ $A d v$, vol. 3, no. 6, Jun 2017

\section{AUTHORS}

First Author - Mabina Agnes, Master candidate, Tongji University, UN Environment-Tongji Institute of Environment for Sustainable Development (IESD): College of Environmental Science and Engineering; Email: agnesmabina70@gmail.com; Phone No +86 19821813097/+255748473346; Address: 1239 Siping Road, Shanghai 200092, China.

Second Author - Awomuti Adeboye, Master candidate, Tongji University, UN Environment-Tongji Institute of Environment for Sustainable Development (IESD): College of Environmental Science and Engineering; Email: boyesky@ yahoo.com; Phone No +86 18521358350/+234 8037887139; Address: 1239 Siping Road, Shanghai 200092, China.

Corresponding Author - QINGHUI HUANG, Tongji University, UN Environment-Tongji Institute of Environment for Sustainable Development (IESD): College of Environmental Science and Engineering: Email: qhhuang@ tongji.edu.cn, Phone No: +86 1362171 3089, Address: 1239 Siping Road, Shanghai 200092, China. 